\title{
A Novel Point Mutation in the Human Insulin Gene Giving Rise to Hyperproinsulinemia (Proinsulin Kyoto)
}

Hideki Yano, " Norikazu Kitano, ${ }^{*}$ Masachika Morimoto, ${ }^{\star}$ Kenneth S. Polonsky," Hiroo Imura, ${ }^{*}$ and Yutaka Seino* *Department of Metabolism and Clinical Nutrition, and Second Division, Department of Medicine, Kyoto University Faculty of Medicine, Kyoto, Japan; ${ }^{\ddagger}$ Department of Medicine, Medical Center for Adult Diseases, Shiga, Japan;

and ${ }^{\S}$ Department of Medicine, The University of Chicago, Chicago, Illinois 60637

\begin{abstract}
We have identified a 65-yr-old nonobese Japanese man with diabetes mellitus, fasting hyperinsulinemia (150-300 pM), and a reduced fasting $\mathrm{C}$-peptide/insulin molar ratio of $\mathbf{2 . 5 - 3 . 0}$. Fasting hyperinsulinemia was also found in his son and daughter. Analysis of insulin isolated from the serum of the proband and his son by reverse-phase high performance liquid chromatography revealed a minor peak coeluting with human insulin and a major peak of proinsulin-like materials. The insulin gene of the patient was amplified by the polymerase chain reaction and the products were sequenced. A novel point mutation was identified in which guanine was replaced by thymine. The substitution gives rise to a new HindIII recognition site and results in the amino acid replacement of leucine for arginine at position 65. These results indicate that the amino-acid replacement prevents recognition of the $C$-peptide- $A$ chain dibasic protease and results in an elevation of proinsulin-like materials in the circulation. Furthermore, in this family the proinsulin-like materials is due to a biosynthetic defect, inherited as an autosomal dominant trait. Rapid detection of this mutation can be accomplished by HindIII restriction enzyme mapping of polymerase chain reaction-generated DNA, which enables us to facilitate the diagnosis and screening. (J. Clin. Invest. 1992. 89:19021907.) Key words: clinical study $\bullet$ high performance liquid chromatography • polymerase chain reaction amplification • restriction site polymorphism
\end{abstract}

\section{Introduction}

Proinsulin, a large molecular weight polypeptide precursor consisting of 86 amino acids, is cleaved into insulin and connecting peptide (C-peptide), which are released into the blood in equimolar amounts (1). In normal subjects, only small amounts of proinsulin enter the circulation, and the concentration of proinsulin is generally less than $20 \%$ of that of insulin (2-4), although proinsulin concentrations are frequently elevated in the patients with diabetes $(4,5)$. It has recently been

Address correspondence and reprint requests to Dr. Hideki Yano, Department of Metabolism and Clinical Nutrition, Kyoto University Faculty of Medicine, 54 Shogoin, Kawahara-cho, Sakyo-ku, Kyoto 606, Japan.

Received for publication 30 September 1991 and in revised form 27 January 1992.

J. Clin. Invest.

(c) The American Society for Clinical Investigation, Inc.

$0021-9738 / 92 / 06 / 1902 / 06 \$ 2.00$

Volume 89, June 1992, 1902-1907 reported, however, that hyperproinsulinemia or hyperinsulinemia may occur in association with structural abnormalities in the proinsulin or insulin molecule due to single nucleotide substitutions in the insulin gene. 10 families have been reported in which some members have single point mutations in the insulin gene that result in amino acid substitutions within the proinsulin molecule. Among them, six families have mutations in which the abnormal insulin has essentially normal immunoreactivity but is biologically defective; in three Japanese families A3-Val was replaced with Leu (insulin Wakayama [6-8]); in two independent families in the United States and Canada B24-Phe was replaced with Ser (insulin Los Angeles [9-11]); and in a single family in the United States B25-Phe was replaced with Leu (insulin Chicago [12, 13]). Few additional families have been identified in which the mutations are associated with hyperproinsulinemia. One of these has a substitution of B10-His with Asp (proinsulin Providence [14, 15]), resulting in a proinsulin that demonstrates markedly altered subcellular sorting behavior $(16,17)$. An additional point mutation in three families has been identified that leads to replacement of Arg- 65 by His (proinsulin Tokyo), and prevents recognition of the C-peptide-A chain dibasic cleavage site (Lys-Arg) by the processing protease in the pancreatic $\beta$ cells $(18-20)$. The present report describes in detail the clinical and laboratory characterization of another diabetic patient who appears to have a novel mutation in the insulin gene.

\section{Methods}

Case report. The patient is a 65 -yr-old nonobese Japanese man who was found to have asymptomatic glucosuria on routine urine examination in 1978. An oral glucose tolerance test (OGTT) ${ }^{1}$ revealed impaired glucose tolerance and hyperinsulinemia (fasting plasma glucose level of $4.6 \mathrm{mM}$ and serum immunoreactive insulin [IRI] level of $150 \mathrm{pM}$ ). In 1985 , he developed polyuria and polydipsia. Physical examination was normal, except for background diabetic retinopathy. Routine laboratory examinations revealed mild hyperglycemia (fasting plasma glucose level of $7.4 \mathrm{mM}$ ) and high level of fasting IRI ( $290 \mathrm{pM})$. Since that time, he has been treated with diet therapy without medications.

Clinical studies. In January 1988, the patient entered the hospital for further clinical and laboratory studies. Serum samples were collected to determine the levels of plasma glucose, IRI, and C-peptide immunoreactivity (CPR) during OGTT at baseline and 30, 60, 90, and $120 \mathrm{~min}$ after oral administration of $75 \mathrm{~g}$ of glucose. For an insulin tolerance test, human actrapid insulin (Novo Nordisk, Copenhagen, Denmark; $0.1 \mathrm{U} / \mathrm{kg}$ ) was injected intravenously after an overnight fast. Counter-insulin hormones, insulin antibodies, and insulin receptor an-

1. Abbreviations used in this paper: CPR, C-peptide immunoreactivity; IRI, immunoreactive insulin; PCR, polymerase chain reaction; PLM, proinsulin-like materials; OGTT, oral glucose tolerance test. 
tibodies were also determined. Levels of fasting glucose and IRI were also measured in his son and daughter.

Characterization of circulating insulin. A stimulated serum sample was obtained from the patient $60 \mathrm{~min}$ after oral administration of $75 \mathrm{~g}$ glucose. $3 \mathrm{ml}$ of serum was fractionated on a Biogel P-30 (Bio-Rad Laboratories, Richmond, CA) column, 1 by $60 \mathrm{~cm}$, equilibrated in borate buffer $\mathrm{pH} 8.6$ containing $0.4 \% \mathrm{BSA}$. The insulin immunoreactivity in each column fraction $(0.5 \mathrm{ml})$ was determined by radioimmunoassay.

Analysis of serum insulin-like immunoreactivity by reverse-phase HPLC. To further characterize the nature of circulating insulin and proinsulin in this patient, serum insulin and proinsulin immunoreactivity were extracted by immunoaffinity chromatography with a nonspecific guinea pig anti-insulin immunoglobulin, coupled to agarose beads (Affi-Gel 10; Bio-Rad Laboratories) using modifications of previously described methods (21). Proinsulin and the proinsulin conversion products demonstrate $100 \%$ cross-reactivity with these antibodies when compared with insulin. Separation of insulin was performed by reverse-phase HPLC, using a Series 4 liquid chromatograph, ISS-100 column oven, and LC-100 recorder/integrator (Perkin-Elmer Corp., Norwalk, CT). Reconstituted immunopurified insulin and proinsulin $(165 \mu \mathrm{l})$ were injected onto an Ultrasphere Ion pair C-18 column, 4.6 $\mathrm{mm} \times 25 \mathrm{~cm}, 5 \mu \mathrm{m}$ particle size (Beckman Instruments, Berkeley, CA) at an elution rate of $1 \mathrm{ml} / \mathrm{min}$ and temperature of $45^{\circ} \mathrm{C}$. Each HPLC run began by equilibrating the column for $15 \mathrm{~min}$ with elution buffer I (20\% acetonitrile and $80 \%$ [0.012 M triethylamine, $0.1 \mathrm{M}$ phosphoric acid, and $0.05 \mathrm{M} \mathrm{NaClO}_{4}$ \{TEAP\}], pH 3.0) at a concentration of $67 \%$ and elution buffer II (50\% acetonitrile and 50\% TEAP, pH 3.0$)$ at $33 \%$. For peptide separation, a linear gradient was produced by increasing the overall concentration of elution buffer II to $46 \%$ over the course of $90 \mathrm{~min}$. The level of immunoreactivity in column fractions that coeluted with the insulin standard was measured in the insulin radioimmunoassay. Immunoreactivity in column fractions that coeluted with the insulin standards of intact proinsulin and the proinsulin conversion intermediates were measured using a proinsulin ELISA in which the two major proinsulin conversion products (des 31,32 and 64,65 proinsulin) demonstrate $100 \%$ cross-reactivity in the assay in relation to proinsulin.

Insulin gene characterization. Genomic DNA prepared from peripheral leukocytes of the proband and his family were used as a template for the polymerase chain reaction (PCR) (22). Oligonucleotide primer pairs used to PCR amplify exon 2 of the insulin gene were nt 484 to 502 and complementary to nt 689 to 708 . For exon 3 of the insulin gene, a set of oligonucleotides used were nt 1435 to 1454 and complementary to nt 1682 to 1700 , as described by Bell et al. (23). $1 \mu \mathrm{g}$ of genomic DNA and $0.1 \mathrm{nmol}$ of each oligoprimer were added to 100 $\mu \mathrm{l}$ of a solution containing the Cetus buffer, $50 \mu \mathrm{M}$ each dNTP, and 2.5 $\mathrm{U}$ of Taq polymerase (Perkin-Elmer Corp.). The mixture was overlaid with mineral oil and placed at $95^{\circ} \mathrm{C}$ for $3 \mathrm{~min}$ before beginning the first cycle. The PCR was carried out for 28 cycles under the following conditions: denaturation for $1 \mathrm{~min}$ at $95^{\circ} \mathrm{C}$; annealing for $1 \mathrm{~min}$ at $58^{\circ} \mathrm{C}$; and extension for $0.7 \mathrm{~min}$ at $72^{\circ} \mathrm{C}$. After amplification, the products were extracted with chloroform, precipitated with ethanol, resuspended with water, electrophoresed through a $1.5 \%$ agarose gel, and visualized with ethidium bromide. The bands corresponding to the exon 2 and exon 3 of the insulin gene were cut out from the gel, blunt ended with Klenow fragment, kinased with T4 polynucleotide kinase, and then subcloned into the SmaI-digested pUC13. The ligated products were then sequenced by the dideoxy chain termination method (24), using universal primers and sequence-specific primers and Sequenase Ver 2.0 (United States Biochemical Corp., Cleveland, $\mathrm{OH}$ ).

Southern blot analysis. $10 \mu \mathrm{g}$ of genomic DNA of controls, the proband, his son, daughter, and cousin were digested with HindIII, electrophoresed through a $0.7 \%$ agarose gel, transferred to a nylon filter, and baked in a vacuum oven at $80^{\circ} \mathrm{C}$ for $2 \mathrm{~h}$. The blot was prehybridized at $42^{\circ} \mathrm{C}$ and hybridized overnight at $42^{\circ} \mathrm{C}$ with the ${ }^{32} \mathrm{P}$ labeled BamHI fragment of phins 96 (a kind gift from Dr. G. I. Bell, The University of Chicago) in a solution as described previously (25).
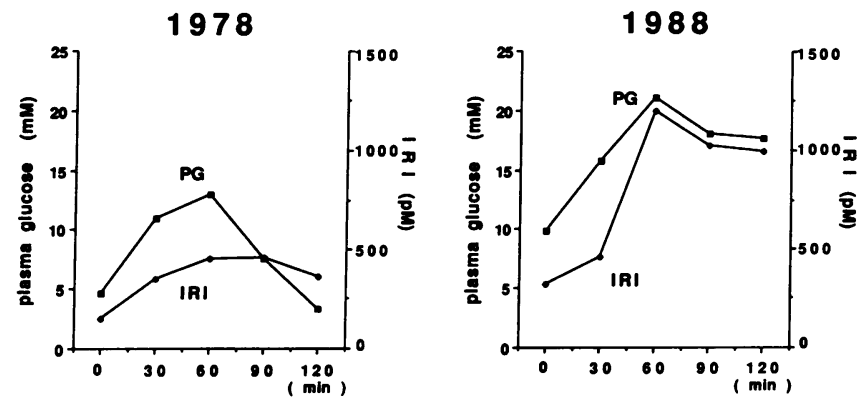

Figure 1. Oral glucose tolerance test profiles. $50 \mathrm{~g}$ glucose in 1978 and $75 \mathrm{~g}$ glucose in 1988 were used. Note that he became diabetic pattern in 1988. PG indicates plasma glucose (mM) and IRI indicates insulin immunoreactivity (pM).

The blot was washed twice at room temperature for $30 \mathrm{~min}$, and then at $55^{\circ} \mathrm{C}$ for $30 \mathrm{~min}$ in $0.1 \times$ standard saline citrate (SSC), $0.1 \%$ SDS before autoradiography.

\section{Results}

Clinical studies. The oral glucose tolerance test revealed that the patient had become diabetic and hyperglycemia occurred despite high levels of IRI (Fig. 1). Both fasting (319 pM) and glucose-stimulated (a peak value of $1,200 \mathrm{pM}$ at $60 \mathrm{~min}$ ) IRI levels were high, and the fasting plasma glucose level was 9.8 $\mathrm{mM}$, which increased to $21.1 \mathrm{mM}$ at $60 \mathrm{~min}$ and remained elevated at $120 \mathrm{~min}$. In contrast to insulin, the plasma CPR levels were relatively normal; fasting and glucose-stimulated CPR levels were 1.0 and $4.7 \mathrm{nM}$, respectively. The resultant CPR/IRI molar ratio was relatively low $(2.5-3.1$ for the patient; $>4.0$ for healthy control). Proband's levels of plasma glucagon ( $88 \mathrm{ng} /$ liter), growth hormone $(0.1 \mu \mathrm{g} /$ liter), thyroid hormone (T3 $1.4 \mathrm{nM}$, T4 $103 \mathrm{nM}$ ), and urinary 17-OHCS $(8.0-18.0 \mu \mathrm{mol} / \mathrm{d})$ were all within normal limits. Moreover, the patient's serum did not contain insulin antibodies or insulin receptor antibodies. To assess insulin sensitivity in vivo, exogenous insulin was injected intravenously. In spite of the high endogenous IRI levels, the patient responded normally to exogenous insulin (Fig. 2).

Family studies. The results of OGTT profiles of his healthy son and daughter and a pedigree are summarized in Fig. 3. Examination of the patient's family by an OGTT revealed that his son and daughter had marked hyperinsulinemia in spite of the normal glucose tolerance. The results indicate that the abnormality in this family is inherited by an autosomal trait.

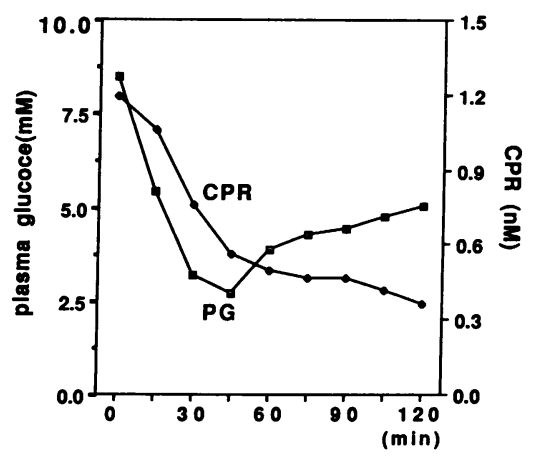

Figure 2. Insulin tolerance test profile. The response of plasma glucose to an intravenous bolus injection of 0.1 $\mathrm{U} / \mathrm{kg}$ of human insulin is shown. The basal glucose level fell from 8.5 $\mathrm{mM}$ to a nadir of 2.7 $\mathrm{mM} 45 \mathrm{~min}$ after the insulin infusion. 


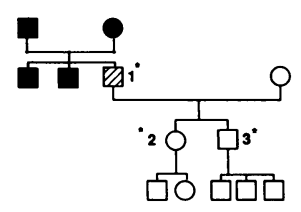

\begin{tabular}{|c|c|c|c|c|c|c|c|c|}
\hline \multirow{4}{*}{$\begin{array}{c}\text { Subject } \\
2\end{array}$} & \multirow{4}{*}{$\begin{array}{l}\text { Ade /Sex } \\
41 \mathrm{~F}\end{array}$} & \multicolumn{7}{|c|}{$75 g$ oGT } \\
\hline & & \multirow{3}{*}{ PG } & $0^{\circ}$ & $300^{\circ}$ & $80^{\circ}$ & \multirow{2}{*}{$\begin{array}{l}90^{\circ} \\
6.5\end{array}$} & \multirow{2}{*}{\multicolumn{2}{|c|}{$5.4(\mathrm{~mm})$}} \\
\hline & & & 4.8 & 6.9 & 7.4 & & & \\
\hline & & & 420 & 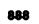 & 1326 & 1416 & 1158 & ( pM) \\
\hline & \multirow{2}{*}{$36 \mathrm{M}$} & PG & 4.3 & 7.3 & 8.8 & 8.2 & 5.3 & $(\mathrm{~mm})$ \\
\hline & & IRI & 228 & 450 & 648 & 990 & 978 & ( pm \\
\hline
\end{tabular}

Figure 3. Pedigree and $75 \mathrm{~g}$ oGTT profiles for his children. Numbered subjects were available for screening. (1) Proband (2) Daughter (3) Son. *Fasting hyperinsulinemia and the diagonal line signifies a diabetic subject.

Gel filtration study. Two well-separated peaks of immunoreactivity were found (Fig. 4). By use of standards of human proinsulin and insulin, the first peak and second peak correspond to proinsulin and insulin, respectively. Thus, the serum of the patient showed a markedly increased peak of proinsulinlike materials (PLM), with a smaller insulin peak. The PLM peak in the patient constituted $87 \%$ of total IRI eluted from the column.

HPLC study. Insulin of the proband and his son purified from peripheral venous blood was applied to an HPLC column. The results are shown in Fig. 5. The elution profiles of insulins demonstrated two peaks of immunoreactive insulins. One small peak ( $\sim 5 \%$ of total IRI) appeared at the position of normal human insulin. Another large peak $(\sim 95 \%$ of total IRI) appeared in a position different from normal human proinsulin or the normal proinsulin conversion products, and was assumed to be due to a structurally abnormal proinsulin.

Insulin gene characterization. To determine the sequence of the patient's insulin gene, genomic DNA from the peripheral blood leukocytes was PCR amplified. Resultant products of exon 2 and exon 3 of the insulin gene were subcloned into pUC13 and nucleotide sequencing was performed. Five of the recombinant pUC13 containing exon 2 showed an entirely normal sequence. On the other hand, two of the recombinant pUC13 containing exon 3 were normal, and the others showed a $G \rightarrow T$ point mutation that corresponds to the second codon position of amino acid residue 65 of Arg (Fig. 6). This site also corresponds to a dibasic site, Lys-Arg at a junction of C-peptide and the A chain, and the point mutation creates a new CTT codon encoding the amino acid leucine (Fig. 7). Moreover, the resultant nucleotide sequences around the point mutation created a HindIII recognition site (AAGCG $\rightarrow$ AAGCTT).

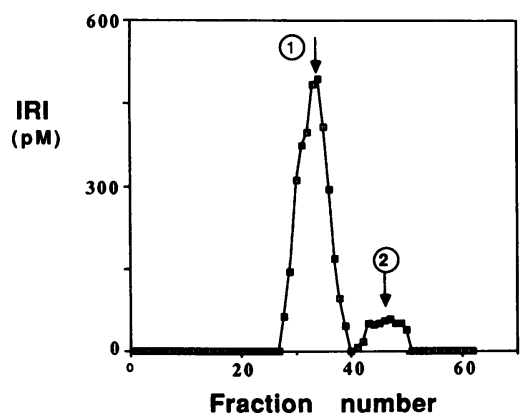

Figure 4. Biogel P-30 column chromatography of $3 \mathrm{ml}$ of serum from the proband. Insulin immunoreactivity was measured in each column fraction using a double antibody method and a human insulin standard. The results are expressed as pM per $100 \mu$ l of each $0.5 \mathrm{ml}$ fraction. Human proinsulin ( $(1)$ and insulin standards (2) eluted from the column in the positions shown by the arrows.

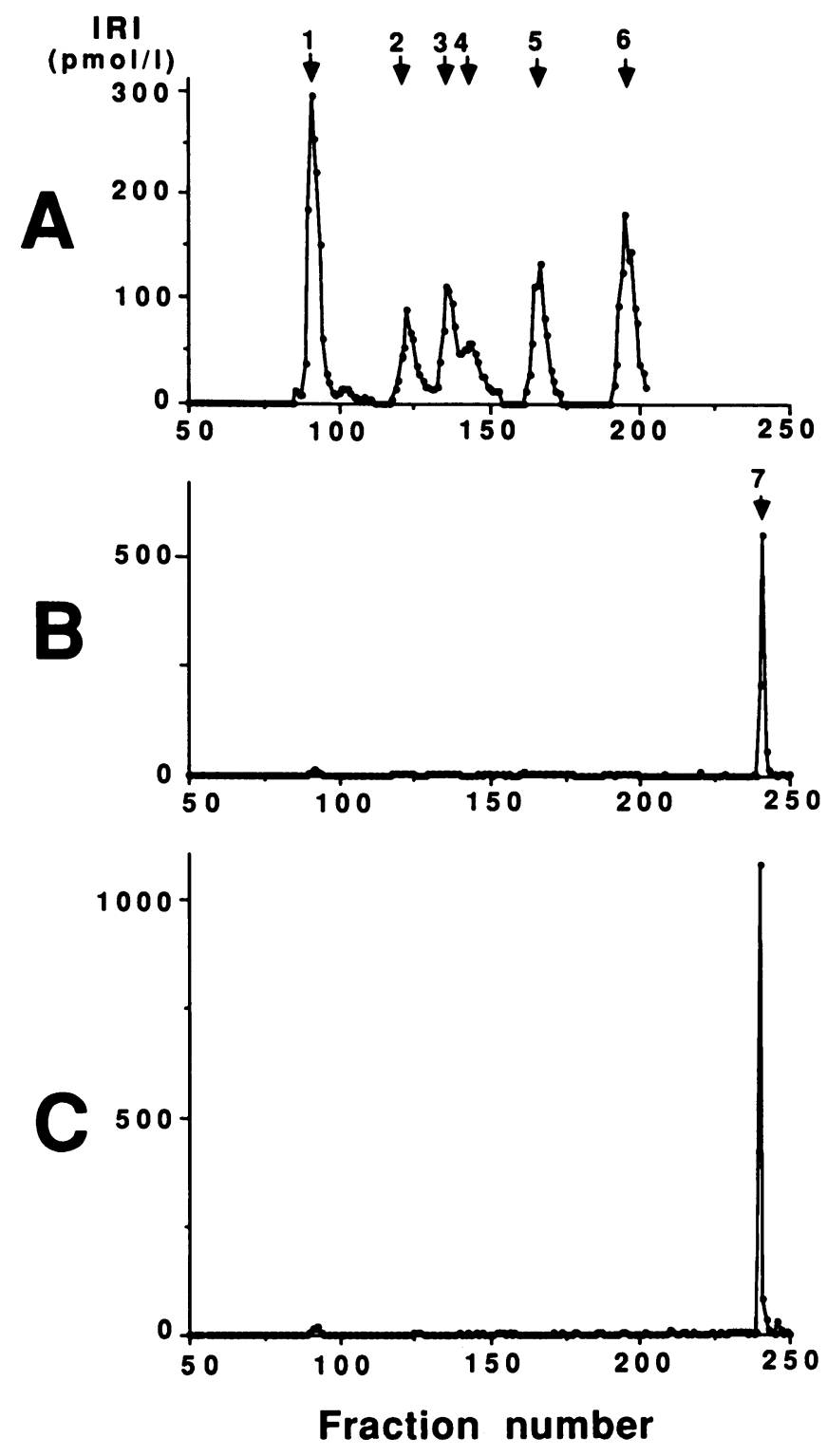

Figure 5. Separation of insulin immunoreactivities in the proband and son by reverse-phase HPLC. Samples were collected $60 \mathrm{~min}$ after $75 \mathrm{~g}$ of oral glucose. $(A)$ Standard human insulin; $(B)$ IRI from the proband; $(C)$ IRI from the son. Each number of the peak indicates as follows: (1) human insulin; (2) ACw Bacics 32,33 split human proinsulin; (3) AC des 31,32 human proinsulin; (4) BCw Basics 65,66 split human insulin; (5) BC des 64,65 human proinsulin; (6) human proinsulin; and (7) mutant proinsulin. HPLC column and the procedures were described in Methods.

Southern blots of HindIII-digested genomic DNA from blood of four family members and two controls were probed with a 1.7-kb human insulin gene fragment from phins96 including the whole insulin structural gene (Fig. 8). An $\sim 11-\mathrm{kb}$ fragment was found in all six persons examined. In addition to this fragment, 5.8- and 5.6-kb fragments were observed in the proband, son, and daughter. These results confirm that three members of the family are heterozygous for the mutation that creates HindIII recognition site. Since the maternal cousin did not show hyperinsulinemia his Southern blot was normal as controls. 


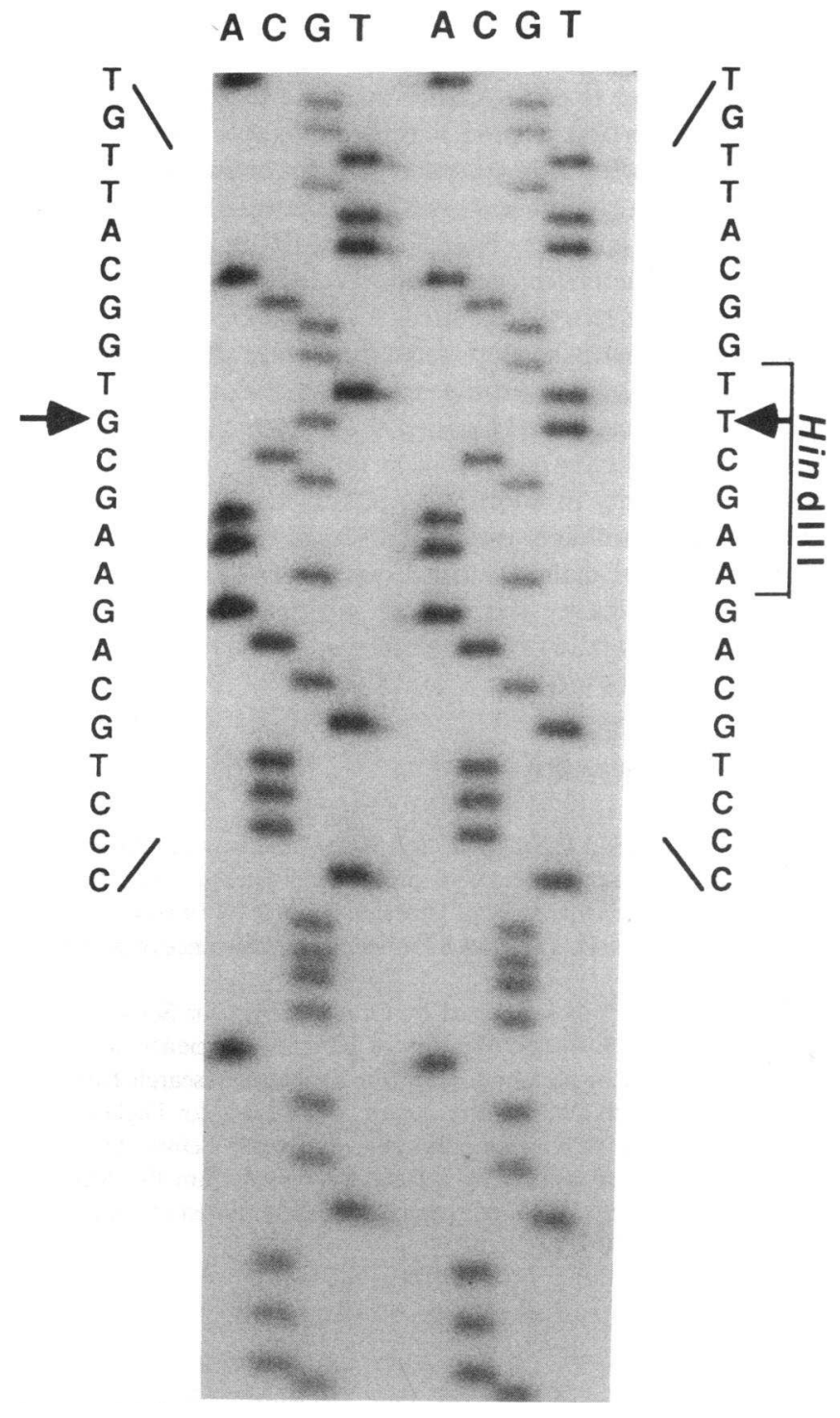

Normal Mutant

Figure 6. Sequence analysis of exon 3 of the insulin gene. The coding strands of both normal and abnormal allele DNA were sequenced by the dideoxy chain termination method. The direction of $5^{\prime} \rightarrow 3^{\prime}$ is from the bottom to upside. A portion of the autoradiogram from a $5 \%$ polyacrylamide/ $8 \mathrm{M}$ urea gel is shown. A single base substitution $(G \rightarrow T)$ is indicated by arrows. The recognition site for HindIII is also indicated.

\footnotetext{
C-chain Junction A-chain Leu Gln Lys Arg Gly Ile

Normal allele CTG CAG AAG CGT GGC ATT $\begin{array}{llllll}62 & 63 & 64 & 65 & 66 & 67\end{array}$

Mutant allele CTG CAG AAG CIT GGC ATT Leu

to $T$ transition at the codon for arginine at position 65 resulted in a leucine substitution and loss of the Lys-Arg pair.
}

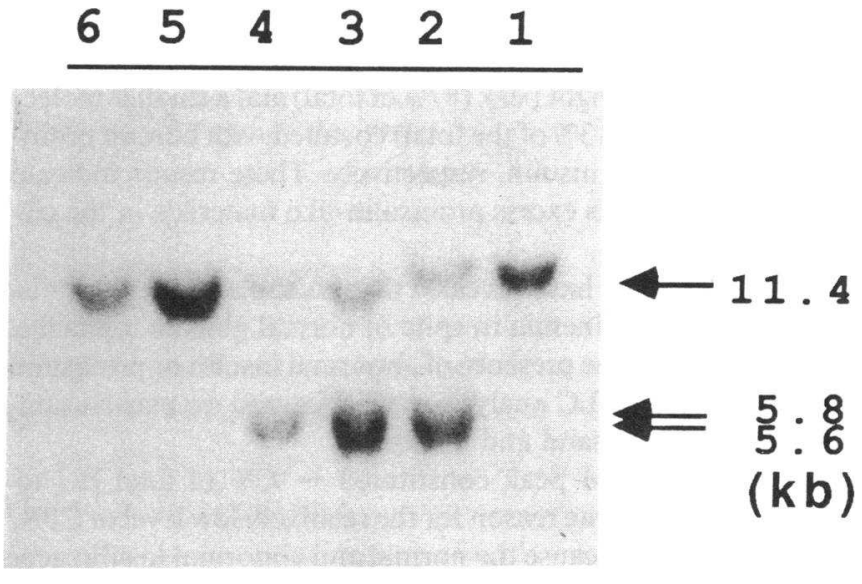

Figure 8. Southern blot analysis of HindIII restriction fragments of genomic DNA from members of the family and normal controls. The hybridizing bands are marked in kilobase pairs. (Lane 1 and 6 ) Normal controls; (Lane 2) proband; (Lane 3) son; (Lane 4) daughter; (Lane 5) maternal cousin of the proband.

\section{Discussion}

We have identified a non-insulin-dependent diabetic patient who presented with glucose intolerance and hyperinsulinemia. The combination of hyperglycemia and hyperinsulinemia suggested an insulin-resistant state or an abnormal insulin gene product from pancreatic $\beta$ cells. In general, insulin resistance can be due to circulating insulin antagonists or a cellular defect in insulin action at a receptor or postreceptor site. However, his circulating counter-insulin hormones were not elevated, and neither insulin antibodies nor insulin receptor antibodies were found. He responded normally to exogenously administered insulin. The results indicated that he was not resistant to exogenous insulin. The fasting CPR/IRI molar ratio was relatively low. This was presumably due to the delayed turnover in vivo of the circulating proinsulin-like materials compared with insulin and is compatible with two other cases of hyperproinsu-

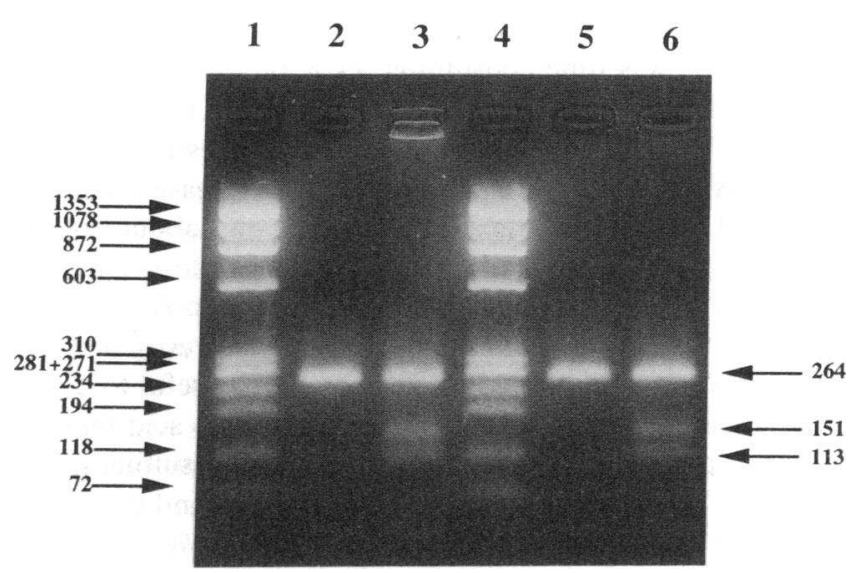

Figure 9. PCR products amplified from genomic DNA including exon 3 of the insulin gene. (Lanes 1 and 4 ) Molecular weight marker; (Lanes 2 and 3) PCR products of exon 3 from the proband; (Lanes 5 and 6) PCR products of exon 3 from the son. Lanes 3 and 6 indicate the HindIII-digested fragments of lane 2 and lane 5 , respectively. The size of molecular weight marker and fragments (bp) is shown in the left and right, respectively. 
linemia. Gel filtration chromatography with Biogel P-30 revealed that the stimulated serum IRI comprised two peaks. The large molecular weight peak ( $87 \%$ of total) and a smaller molecular weight peak ( $13 \%$ of the total) coeluted with human proinsulin and human insulin, respectively. These results indicate that the patient has excess proinsulin-like materials in the circulation.

Family studies have revealed that his son and daughter displayed hyperinsulinemia in spite of normal glucose tolerance. To demonstrate the presence of abnormal insulin or proinsulin in this family, HPLC analysis was performed on plasma samples from the proband and his son.

The large PLM peak constituted $\sim 95 \%$ of total IRI resulted from the same reason for the relatively low level of CPR/ IRI molar ratio because the normal and abnormal insulin gene should be expressed equally. This peak of the family appeared at the more hydrophobic position than normal proinsulin, and did not coincide with human A-C proinsulin (des 31, 32 proinsulin) peak, while previously reported Proinsulin Tokyo or Proinsulin Providence has a peak of A-C proinsulin.

Further evidence in favor of a hypothesis that the PLM in this family resulted from an abnormality in the insulin gene was obtained from the nucleotide sequence of the PCR-amplified insulin gene fragments. A $G \rightarrow T$ point mutation was found that corresponds to the second codon position of amino acid residue 65 of Arg at a junction of C-peptide and A chain. By contrast, Proinsulin Tokyo also has a single base $\mathrm{G}$ to $\mathrm{A}$ substitution at the same nucleotide position, resulting in a histidine substitution at Arg-65 (26). Thus, the disappearance of the dibasic pair (Lys-Arg) blocks the maturation of insulin. Because PCR products of the insulin gene were sequenced, an inherent uncertainty in this analysis was the possibility that the coding mutation could be due to a PCR artifact. Attempts to verify the mutation directly in the genomic DNA by the appearance of the predicted HindIII fragments after Southern blot analysis yielded evident results. Moreover, the novel point mutation at the codon for Arg-65 were also confirmed by separate cloning and sequencing of the normal and abnormal insulin alleles.

The prevalence of this novel mutation in the insulin gene among the general population is unknown. Since Southern blot analysis was time consuming, PCR products containing exon 3 were analyzed by HindIII digestion. When the product is divided into three fragments with HindIII digestion, the heterozygous mutation of this newly identified disease should be easily and rapidly confirmed (Fig. 9). Thus, only about 4 or $5 \mathrm{~h}$ from the start of PCR to the end of agarose gel electrophoresis is required, while screening of Proinsulin Tokyo is time consuming because it does not create any site of restriction enzyme. These techniques with PCR should be useful to detect other mutant insulin genes giving rise to amino acid replacements at position $\mathrm{Phe}^{\mathrm{B} 24}$ and $\mathrm{Phe}^{\mathrm{B} 25}$, thereby resulting in the loss of an MboII restriction site. Family studies and their insulin gene analysis revealed that the abnormality was an autosomal dominant trait as other reported mutations in the insulin gene.

It is interesting to consider the reasons why the patient with mutant insulin gene has diabetes. Family studies showed that two children with the mutation were not diabetic. There were no differences in the results of HPLC profiles between those with and without diabetes. The reasons for the differences in their metabolic states are not clear. Although the patient is not resistant to exogeneous insulin, it cannot be concluded that he has no resistance to endogeneous insulin. Moreover, although he responds to oral glucose with considerable IRI secretory response, normal insulin secretion may not be enough to maintain the plasma glucose level within the normal range because normal insulin is only $\sim 5-13 \%$ of total IRI. It is possible that other genetic factors may determine whether individuals who secrete mutant forms of insulin develop diabetes. Non-insulindependent diabetes develops most frequently after middle age. As Nanjo et al. discussed the reasons (27), expression of diabetes might be explained by other diabetogenic factors, genetic or acquired, affecting a defect in insulin secretion or peripheral insulin sensitivity in addition to possessing a mutant insulin gene. It seems unlikely that mutations in the insulin gene are major causes of diabetes. However, the analysis of development of diabetes by the mutant proinsulin will provide a deeper understanding of the pathogenesis of non-insulin-dependent diabetes mellitus.

\section{Acknowledgments}

We are very grateful to Dr. G. I. Bell, The University of Chicago, for supplying the human insulin gene probe. We would also like to thank Dr. S. Seino, The University of Chicago, for helpful suggestions with this study, and Ms. H. Tachikawa for her expert assistance in preparing this manuscript.

This research was supported by Grants-in-Aid for Scientific Research 02671093 from the Ministry of Education, Science, and Culture, Japan, and in part by a grant for Diabetes Research from the Ministry of Health and Welfare, Japan, and a grant for Diabetes Research from Ohtsuka Pharmaceutical Co., Ltd. (to Y. Seino). This work was also supported in part by a Research Grant from the National Institutes of Health (DK-31842) and the Diabetes Research and Training Center (DK-20595).

\section{References}

1. Steiner, D. F., and P. E. Oyer. 1967. The biosynthesis of insulin and a probable precursor of insulin by a human islet cell adenoma. Proc. Natl. Acad. Sci. USA. 57:473-480.

2. Horwitz, D. L., J. I. Starr, M. E. Mako, W. G. Blackard, and A. H. Rubenstein. 1975. Proinsulin, insulin, and C-peptide concentrations in human portal and peripheral blood. J. Clin. Invest. 55:1278-1283.

3. Heding, L. G. 1977. Specific and direct radioimmunoassay for human proinsulin in serum. Diabetologia. 13:467-474.

4. Rainbow, S. J., J. S. Woodhead, D. K. Yue, S. D. Luzio, and C. N. Hales 1979. Measurement of human proinsulin by an indirect two-site immunoradiometric assay. Diabetologia. 17:229-234.

5. Kitabchi, A. E. 1983. Proinsulin and C-peptides. In Diabetes Mellitus. M. Ellenberg and H. Ritkin, editors. Theory and Practice. 3rd ed. Medical Examination Publishing Co., Inc., Amsterdam. 97-117.

6. Nanjo, K., T. Sanke, M., Miyano, K. Okai, R. Sowa, M. Kondo, S. Nishimura, K. Iwo, K. Miyamura, B. D. Given, et al. 1986. Diabetes due to secretion of a structurally abnormal insulin (insulin Wakayama): clinical and functional characteristics of $\left[\mathrm{Leu}^{\mathrm{A} 3}\right]$ insulin. J. Clin. Invest. 77:514-519.

7. Nanjo, K., M. Miyano, M. Kondo, T. Sanke, S. Nishimura, K. Miyamura, K. Inouye, B. D. Given, S. J. Chan, K. S. Polonsky, et al. 1987. Insulin Wakayama: familial mutant insulin syndrome in Japan. Diabetologia. 30:87-92.

8. Iwamoto, Y., H. Sakura, Y. Ishii, R. Yamamoto, S. Kumakura, Y. Sakamoto, A. Matsuda, and T. Kuzuya. 1986. A new case of abnormal insulinemia with diabetes: reduced insulin values determined by radioreceptor assay. Diabetes. 35:1237-1242.

9. Haneda, M., S. J. Chan, S. C. M. Kwok, A. H. Rubenstein, and D. F. Steiner. 1983. Studies on mutant human insulin genes: identification and sequence analysis of a gene encoding $\left[\mathrm{Ser}^{\mathrm{B24}}\right]$ insulin. Proc. Natl. Acad. Sci. USA. 80:6366-6370.

10. Haneda, M., K. S. Polonsky, R. M. Bergenstal, J. B. Jaspan, S. E. Shoelson, P. M. Blix, S. J. Chan, S. C. M. Kwok, W. B. Wisher, A. Zeidler, et al. 1984. 
Familial hyperinsulinemia due to a structurally abnormal insulin: definition of an emerging new clinical syndrome. $N$. Engl. J. Med. 310:1288-1294.

11. Shoelson, S., M. Fickova, M. Haneda, A. Nahum, G. Musso, E. T. Kaiser, A. H. Rubenstein, and H. Tager. 1983. Identification of a mutant insulin predicted to contain a serine-for-phenilalanine substitution. Proc. Natl. Acad. Sci. USA. 80:7390-7394.

12. Tager, H., B. Given, D. Baldwin, M. Mako, J. Markese, A. Rubenstein, J. Olefsky, M. Kobayashi, O. Kolterman, and P. Poucher. 1979. A structurally abnormal insulin causing human diabetes. Nature (Lond.). 281:122-125.

13. Kwok, S. C. M., D. F. Steiner, A. H. Rubenstein, and H. S. Tager. Identifcation of a point mutation in the human insulin gene giving rise to a structurally abnormal insulin (Insulin Chicago). Diabetes. 32:872-875.

14. Gruppuso, P. A., P. Gorden, C. R. Kahn, M. Cornblath, W. P. Zeller, and R. Schwartz. 1984. Familial hyperproinsulinemia due to a proposed defect in conversion of proinsulin to insulin. N. Engl. J. Med. 311:629-634.

15. Chan, S. J., S. Seino, P. A. Gruppuso, R. Schwartz, and D. F. Steiner. A mutation in the B chain coding region is associated with impaired proinsulin conversion in a family with hyperproinsulinemia. Proc. Natl. Acad. Sci. USA. 84:2194-2197.

16. Carroll, R. J., R. E. Hammer, S. J. Chan, H. H. Swift, A. H. Rubenstein, and D. F. Steiner. 1988. A mutant human proinsulin is secreted from islets of Langerhans in increased amounts via an unregulated pathway. Proc. Natl. Acad. Sci. USA. 85:8943-8947.

17. Burgess, T. L., and R. B. Kelly. 1987. Constitutive and regulated secretion of proteins. Annu. Rev. Cell Biol. 3:243-293.

18. Gabbay, K. H., R. M. Bergenstal, J. Wolff, M. E. Mako, and A. H. Rubenstein. 1979. Familial hyperproinsulinemia: partial characterization of circulating proinsulin-like material. Proc. Natl. Acad. Sci. USA. 76:2881-2885.

19. Barbetti, F., N. Raben, T. Kadowaki, A. Cama, D. Accili, K. H. Gabbay, J. A. Merenich, S. I. Taylor, and J. Roth. 1990. Two unrelated patients with familial hyperproinsulinemia due to a mutation substituting histidine for arginine at position 65 in the proinsulin molecule: identification by direct sequencing of genomic deoxyribonucleic acid amplified by polymerase chain reaction. $J$. Clin. Endocrinol. \& Metab. 71:164-169.

20. Kanazawa, Y., M. Hayashi, M. Ikeuchi, M. Kasuga, Y. Oka, H. Sato, K. Hiramatsu, and K. Kosaka. 1979. Familial proinsulinemia: a rare disorder of insulin biosynthesis. In Proinsulin, Insulin, C-Peptide. S. Baba, T. Kaneko, and N. Yanaihara, editors. Excerpta. Medica, Amsterdam. 262-269.

21. Given, B. D., R. H. Cohen, S. E. Shoelson, B. H. Frank, A. H. Rubenstein, and H. S. Tager. 1985. Biochemical and clinical implications of proinsulin conversion intermediates. J. Clin. Invest. 76:1398-1405.

22. Saiki, R. K., D. H. Gelfand, S. Stoffel, S. J. Scharf, R. Higuchi, G. T. Horn, K. B. Mullis, and H. A. Erlich. 1988. Primer-directed enzymatic amplification of DNA with a thermostable DNA polymerase. Science (Wash. DC). 239:487-491.

23. Bell, G. I., R. L. Pictet, W. J. Rutter, B. Cordell, E. Tischer, and H. M. Goodman. 1977. Sequence of the human insulin gene. Nature (Lond.). 284:2632.

24. Sanger, F., S. Nicklen, and A. R. Coulson. 1977. DNA sequencing with chain-terminating inhibitors. Proc. Natl. Acad. Sci. USA. 74:5463-5467.

25. Yano, H., Y. Seino, N. Inagaki, Y. Hinokio, T. Yamamoto, K. Yasuda, K. Masuda, Y. Someya, and H. Imura. 1991. Tissue distribution and species difference of the brain type glucose transporter (GLUT3). Biochem. Biophys. Res. Commun. 174:470-477.

26. Shibasaki, Y., T. Kawakami, Y. Kanazawa, Y. Akanuma, and F. Takaku. 1985. Posttranslational cleavage of proinsulin is blocked by a point mutation in familial hyperproinsulinemia. J. Clin. Invest. 76:378-380.

27. Nanjo, K., T. Sanke, M. Kondo, S. Nishimura, M. Miyano, J. Linuma, K. Miyamura, K. Inouye, B. D. Given, K. S. Polonsky, et al. 1986. Mutant insulin syndrome: identification of two families with [ $\left.\mathrm{Leu}^{{ }^{3}}\right]$ insulin and determination of its biological activity. Trans. Assoc. Am. Physicians. 99:132-142. 